\title{
Os dois galangas: narrativas afro-diaspóricas em Chico Rei e Rincón Sapiciência
}

\author{
Ezequiel Santos Cruz ${ }^{\mathrm{i}}$
}

\begin{abstract}
RESUMO
O presente artigo busca apresentar um diálogo de narrativas, a partir de elementos historiográficos do rei Galanga do Congo, mais conhecido no Brasil como "Chico Rei", e de Galanga Livre, incorporado por Rincón Sapiência em seu álbum de estreia. O artista, que toma emprestado o nome "Galanga" para atribuir ao seu álbum, remonta a saga do rei do Congo, dessa vez, enfrentando os resquícios da escravidão e o racismo no Brasil contemporâneo. Sapiência, que também é conhecido como Manicongo, nome dado aos reis do Congo durante a era imperial africana, ressignifica a história de Galanga "Chico Rei”, trazendo-o para o século XXI. A obra Galanga Livre funciona como um conto com início, meio e fim. A narrativa de luta, sofrimento e resistência do rei Galanga do Congo é somada, em Sapiência, ao amor, diversão e autoestima. Chico Rei e Galanga Livre dialogam sobre resistência negra, anti-escravagismo e, sobretudo, liberdade. A partir de um estudo comparatista, o trabalho tece uma abordagem decolonial, tendo como escopo dois reis - um africano e outro afro-brasileiro, ambos enfrentando os dissabores da escravização no Brasil contemporâneo.
\end{abstract}

Palavras-chave: Rap; Literatura; Música; Poesia; Hip Hop.

\begin{abstract}
This article seeks to present a dialogue of narratives based on historiographical elements of King Galanga of Congo, better known in Brazil as "Chico Rei", and "Galanga Livre", a character incorporated by rapper Rincón Sapiência in his debut album. Borrowing the name "Galanga" to his album's title, the artist retraces the saga of the king of Congo, this time facing the remnants of slavery and racism in contemporary Brazil. Sapiência, who is also known as Manicongo - the name given to the kings of Congo during the African Imperial era, re-signifies the story of Galanga "Chico Rei" by bringing it into the $21^{\text {st }}$ century. Galanga Livre works like a short story with a beginning, a middle and an end. King Galanga's story of struggle, suffering, and resistance is added, in Sapiência, to love, fun, and self-esteem. Chico Rei and Galanga Livre dialogue about Black resistance, anti-slavery, and, above all, freedom. In a comparative study, we weave a decolonial approach with the scope of two kings - one African and the other Afro-Brazilian -, both facing the discomforts of slavery in contemporary Brazil.
\end{abstract}

Keywords: Rap; Literature; Music; Poetry; Hip Hop.

i Mestrando no Programa de Pós-Graduação em Literatura e Cultura da Universidade Federal da Bahia (PPGLitCult-UFBA). ezequielufba@bol.com.br 


\section{INTRODUÇÃO}

Como intelectual negro, elaboro este ensaio a partir de um olhar "de dentro", teórica, crítica e literariamente falando, já que acumulo mais de uma década como membro do movimento Hip Hop, ativista raper(eiro) e integrante do grupo “Universidade Rap". Porém, esses atributos, embora importantes, não irão desvencilhar minha postura crítica acerca do tema que pretendo tratar.

Galanga Livre é um trabalho excepcional no cenário do rap nacional, do movimento Hip Hop e da indústria cultural como um todo, e Rincón Sapiência, um grande artista e intelectual afro-diaspórico. A ausência de pesquisas acadêmicas sobre o autor e suas obras trouxe-me inquietações. Partindo do meu lugar de fala, como rapeiro e crítico musical, em especial da música rap, afirmo que seria contribuir para o epistemicídio não escrever sobre um disco que narra a história de um rei africano que foi vendido como escravo e trazido para o Brasil. Rincón Sapiência não apenas conta a história de Galanga, rei do Congo, mas também a história do Brasil como ela é e deve ser contada, pois os apagamentos étnico, identitário e cultural provocados pelo sistema escravagista-colonial renomeou o rei congolês com o nome de Francisco. Essa prática de "batizar" os africanos escravizados com nomes de santos católicos vigorou durante todo o período escravocrata no Brasil.

O rei Galanga, já com o nome de colonizado/escravizado Francisco, recusava ser chamado de "escravo" pelos traficantes negreiros - mesmo em condição subalternizada, Galanga afirmava-se rei do Congo. Trabalhou arduamente na mina de ouro do major Augusto, comprador de escravizados, em Minas Gerais, até comprar a sua própria alforria e, posteriormente, a de muitos negros escravizados. Rincón Sapiência ressignifica a história do rei do Congo em Galanga Livre. O Galanga rinconiano é um escravizado que conquista sua liberdade assassinando um senhor de engenho. A narrativa é enredada pela fuga de Galanga, o "Negro fujão" que se envolve em uma sucessão de acontecimentos desenhados pelas voz, rimas e pelos versos de Rincón Sapiência. 
Francisco era também chamado de Chico pelos senhores de engenho e companheiros escravizados que trabalhavam na mina conhecida como Mina da Encardideira, hoje chamada Mina de Chico Rei. Como sempre se intitulava monarca e por ter lutado bravamente para a libertação dos negros africanos e afro-brasileiros escravizados, é considerado o primeiro abolicionista do Brasil.

\section{DADOS BIOGRÁFICOS DE CHICO REI E RINCÓN SAPIÊNCIA}

Galanga Rei do Congo era um monarca e sumo-sacerdote do deus ZambiApungo. Era também líder de uma numerosa tribo congolesa. Galanga passou a ser prisioneiro. Após uma dura guerra no Congo com outra liderança africana, sua mulher, filhos e toda a corte também foram aprisionados. Vendido como escravo e comprado por comerciantes portugueses, Galanga foi transportado para o Brasil, juntamente com sua família. No entanto, sua mulher, a rainha Djalô, e sua filha, a princesa Itulo, são atiradas ao mar, segundo os traficantes negreiros, a fim de reduzir o peso da embarcação devido a uma tempestade. Estima-se que metade dos escravizados foi lançada no mar. Outras narrativas dizem que a ira dos deuses africanos provocou a tempestade em altomar, e, para acalmá-la, os traficantes negreiros ofereceram a rainha e a princesa. O rei do Congo desembarcou em terras brasileiras em 1740, apenas com o seu filho no Valongo, porto do Rio de Janeiro.

Danilo Albert Ambrósio nasceu em São Paulo, na Cohab, situada na periferia da cidade. É rapeiro, ${ }^{1}$ produtor musical e beatmaker. ${ }^{2}$ Em 2017, lançou o álbum de estreia Galanga Livre e, no ano seguinte, o próprio selo, "Mgoma". Seu vulgo ${ }^{3}$ é Rincón Sapiência e/ou Manicongo, que, traduzido da língua africana, kicongo significa "rei do Congo". Embora tenha lançado seu primeiro álbum recentemente, Rincón Sapiência iniciou sua carreira no movimento Hip Hop em 2000. Ele assinava os vulgos como Rincón $\mathrm{X}^{4}$ e MC Shato, também lançou alguns singles, ${ }^{5}$ o $\mathrm{EP}^{6}$ SP Gueto BR, e o CD promocional promotrampo vol. 1. O vulgo Manicongo que Rincón adotou faz referência ao Reino do Congo fundado no século XIV, cujo rei era intitulado homonimamente. Parte da família de Rincón é do Estado de Minas Gerais, local onde também viveu Chico Rei. A avó de Sapiência era organizadora de manifestações culturais afrobrasileiras, como o tambor de crioula, a umbigada e a congada (referente ao Congo). 
Chico organizou uma festa cujo tema era "a coroação do rei do Congo", que mais tarde receberia o nome de "congada". Vestiu-se de rei e foi novamente coroado, passando a ser chamado de Chico Rei.

\section{OS DOIS GALANGAS: NARRATIVAS AFRO-DIASPÓRICAS EM CHICO REI E RINCÓN SAPIÊNCIA}

Este item do ensaio propõe uma abordagem comparatista entre duas narrativas orais: uma histórico-biográfica e outra artístico-literária. Apesar das diferenças textuais, ambas relatam/contam a história de um rei do Congo chamado Galanga. Para tanto, convocarei suportes teórico-críticos que deem conta das (re)flexões que surgirão ao decorrer das linhas e parágrafos deste trabalho.

Os recortes temporais nos quais Galanga Rei do Congo e Galanga Livre estão inseridos não os impedem que estabeleçam entrelaçamentos, já que estou trabalhando com narrativas afro-diaspóricas baseadas na cosmovisão africana, em que a noção de temporalidade difere da cronologia ocidental, calcada em uma linearidade. A saga do lendário Chico Rei deu-se em 1740, enquanto Galanga Livre, lançado pelo rapper Rincón Sapiência, em 2017. Para Leda Martins (1997, p. 75), essa percepção cósmica e filosófica entrelaça, no mesmo circuito de significância, o tempo, a ancestralidade e a morte. A primazia do movimento ancestral, fonte de inspiração, matiza as curvas de uma temporalidade espiralada, na qual os eventos, desvestidos de uma cronologia linear, estão em processo de uma perene transformação. Nascimento, maturação e morte tornam-se, pois, contingências naturais, necessárias na dinâmica mutacional e regenerativa de todos os ciclos vitais e existenciais. Nas espirais do tempo, tudo vai e tudo volta.

A história do rei Galanga, narrada por Rincón Sapiência no álbum Galanga Livre, é recriada com todos os recursos que a literatura e a literariedade oferecem. Há uma linha tênue entre ficção e realidade, e também entre os dois Galangas: o personagem rinconiano tem por nome Galanga e é um escravizado que "toma à força" sua liberdade após assassinar um senhor de engenho. O caráter intertextual é muito bem articulado pelo autor, pois, como já foi dito, o verdadeiro nome de Chico Rei era 
Galanga. Rincón literaliza a história de Galanga vivendo em liberdade no Brasil contemporâneo. Na introdução do álbum, o rapper evidencia a temática de sua obra.

\begin{abstract}
Salve, salve! Vamo seguindo aqui nas nossas transmissões, aqui no Novembro Manicongo, com a música de Rincón Sapiência, música que foi inspirada no conto fictício do escritor Danilo Albert Ambrósio, que conta a história do escravo Galanga, que gerou uma grande reviravolta no engenho, a partir do momento que cometeu um crime bárbaro (SAPIÊNCIA, 2017).
\end{abstract}

Considero indispensável discorrer um pouco mais sobre o texto que é a faixa ${ }^{7}$ de abertura da obra de Sapiência, transcrita acima. Como estou trabalhando com narrativas afro-diaspóricas, não posso perder de vista a afro-diasporicidade presente nas mesmas. Rincón estabelece uma interconexão entre valores ancestrais africanos e africanistas ao nomear seu programa de rádio "Novembro Manicongo". ${ }^{8}$ A primeira palavra refere-se ao mês em que um dos mais importantes líderes da luta antiescravagista no Brasil foi executado, Zumbi dos Palmares. ${ }^{9} \mathrm{O}$ segundo nome faz referência ao título dado aos reis do Congo. Concordo com a autora Denise Carrascosa, quando a mesma postula que:

\begin{abstract}
A "afro-diasporicidade", mais que um conceito, pode ser usado como sua força agonística, que destitui e reconstitui territórios. Seus deslocamentos, movimentações e reversões contraculturais negras se disseminam em vários espaços e tempos, desfazendo a unidade centrípeta da nação e suas ilusões narrativas subalternizantes; gerando uma teia de performances que não se reunificam ou retornam para serem aprisionadas, em um lugar do passado mítico africano, ao contrário, a partir de sua pujança, projetam-se como potência contemporânea, portanto ressonante e intempestiva (CARRASCOSA, 2016, p. 65)
\end{abstract}

A história de Chico Rei é registrada através da tradição oral, pois não há documentos biográficos escritos sobre o rei do Congo. Entretanto, a festa do congado, ${ }^{10}$ a mina de Chico Rei, localizada na cidade de Ouro Preto, em Minas Gerais, e outras manifestações/produções artístico-culturais afro-brasileiras, como o álbum Galanga Livre, mantêm viva a memória do monarca congolês. Para o griot ${ }^{11}$ Amadou Hampaté Bâ, o documento oral é a base histórica da África e dos povos africanos.

\footnotetext{
Quando falamos de tradição em relação à história africana, referimo-nos à tradição oral, e nenhuma tentativa de penetrar a história e o espírito dos povos africanos terá validade a menos que se apoie nessa herança de conhecimentos de toda espécie, pacientemente transmitidos de boca a ouvido, de mestre a discípulo, ao longo dos séculos. Essa herança ainda não se perdeu e reside na memória da última geração de grandes depositários, de quem se pode dizer são a memória viva da África (HAMPATÉ BÂ, 2010, p. 181).
} 
Alguns historiadores, antropólogos, escritores e pesquisadores de Literatura Brasileira, imbuídos de preconceito racial, encabeçados pelo ocidentalismo, proferem comentários equivocados acerca da história de Chico Rei. Um dos dois únicos trabalhos que encontrei no banco de teses da CAPES sobre Chico Rei, uma dissertação de mestrado em Literatura Brasileira, cujo autor é também mineiro, argumenta o seguinte:

\begin{abstract}
O que desagradava e enojava Chico Rei era a presença de portugueses como senhores da exploração de muitas minas. A eles eram creditados o ônus de tudo de mal que lhe aconteceu, nos últimos tempos de sua vida. No entanto, servia com lealdade ao seu senhor mineiro, filho de paulistas. Como seus patrícios chegados no mesmo barco trabalhavam na Vila e circunvizinhanças, embora não se vissem, ele sabia-lhes as notícias. Seu filho Muzinga trabalhava no mesmo eito e resistia ao áspero destino com a coragem herdada e a respeitada capacidade de adaptação de sua raça. Para a infelicidade de sua raça, esse poder de adaptação foi a grande causadora de tanto sofrimento e dor, e um bem para o Brasil, que teve nesse infeliz povo o melhor elemento na exploração de suas riquezas mineral e na resistência física de sua miscigenação (GOUVEIA, 2015, p. 57).
\end{abstract}

Essa visão preconceituosa e colonial-eurocêntrica é adotada por diversos intelectuais, sobretudo no campo das ciências humanas brasileiras, e na literatura há uma duplicação de tal visão. O romance Chico Rei, escrito pelo autor mineiro Agripa Vasconcelos, deixa evidente o pensamento racista-europeísta que ainda permeia os imaginários de alguns escritores e intelectuais brasileiros. Segundo o autor, "Chico por várias vezes garantiu ao governador paz entre os escravos de todas as capitanias. Pelo sucesso de seu trabalho de concórdia em Vila Rica, julgara a negralhada enraivecida no sertão das Gerais" (VASCONCELOS, 1964, p. 170).

$\mathrm{O}$ argumento que proponho acima é legítimo e não pode nem deve ser reduzido a discurso de militância, já que o trabalho em questão possui rigor científico suficiente para não ser taxado como tal, pois o estudo sobre questões étnicas, sobretudo ligadas aos povos africanos e afrodescendentes, partindo de um pressuposto ocidental, geralmente apresenta grandes lacunas, como as deixadas pelo médico e escritor Agripa Vasconcelos em seu trabalho, acima citado.

Ainda sobre a visão vasconceliana sobre a figura mitológica Chico Rei, devo concordar com Kofi Aniydoho e Helen Lauer, quando ambos pontuam que parte substancial dos estudos de perspectiva ocidental, "ao promover viés eminentemente individualista, subverte tradições, princípios e valores locais responsáveis pela 
orientação comunitária das sociedades africanas e simplifica sua rica e complexa diversidade étnica e cultural" (LAUER; ANYIDOHO, 2016, p. 8).

O discurso produzido por um sistema racista-hegemônico, além de negar saberes não livrescos, como as tradições e/ou narrativas orais africanas e indígenas, falsifica dados sobre esses povos. A historiografia geral, antropológica ou literária calcada no Ocidente também se apropria dos saberes, das produções culturais e/ou artísticoliterárias não ocidentais. Isso ocorreu na música, com o rock nos Estados Unidos, nomeando Elvis Presley como "O rei do rock", secundarizando Chuck Berry e Little Richard, assim como na literatura brasileira, cuja crítica literária branca não reconhece Lima Barreto como precursor do modernismo, só para citar alguns exemplos. A esse conjunto de práticas, o autor Henrique Freitas denomina de "pilhagem epistemológica".

\begin{abstract}
Chamamos pilhagem epistemológica uma das perversões do epistemicídio que consiste na subtração ou apropriação de elementos constitutivos dos saberes subalternos (aqueles que constituem as cosmogonias indígenas, africanas negro-brasileiras, ou as tecnologias sociais e linguísticas dos pobres) sem qualquer agenciamento e muitas vezes mesmo referenciação dos sujeitos dessas gnoses. Nesse sentido é pilhagem, porque saqueia-se o outro naquilo que se reconhece como mais valioso, incorporando em seu repertorio como estratégia de produção individual ou de um grupo completamente diferente daquele que gestou os saberes em foco (FREITAS, 2016, p. 39).
\end{abstract}

\title{
DE GALANGA REI DO CONGO A GALANGA LIVRE
}

Neste terceiro e último item do ensaio, pretendo explorar as (re)significações elaboradas pelo autor Rincón Sapiência acerca da narrativa oral do rei Galanga. Para isso, trarei alguns trechos de duas músicas presentes no álbum Galanga Livre, trechos esses que irão além de objetos literários, funcionando como vetores teóricos, somados a outros referenciais africanos e afro-diaspóricos que darão embasamento ao que proponho realizar.

Na segunda música do álbum, intitulada "Crime Bárbaro", Rincón narra a fuga de Galanga após o assassinato do senhor de engenho. Essa canção possui um caráter excepcional e singular, pois desmistifica o heroísmo atribuído à princesa Isabel pela assinatura da Lei Áurea e traz para o protagonismo do acontecimento o rei Galanga, que, na condição de escravizado, lidera rebeliões e influencia uma gama de escravizados africanos e afro-brasileiros a aderirem à causa. Estrategicamente, Rincón Sapiência 
lançou o videoclipe de "Crime Bárbaro" no dia 13 de maio, ${ }^{12}$ data em que definitivamente é assinada a proibição da escravidão no Brasil.

\author{
Boatos correm, eu também \\ Me sinto como um herói, isso me faz bem \\ Escravos me colocam como um rei \\ Porque o senhor de engenho fui eu que matei! (SAPIÊNCIA, 2017).
}

Chico rei comprou a própria liberdade e a de muitos escravizados, e a Mina da Encardideira, que fora dada como esgotada por Major Augusto, homem que havia comprado o rei Galanga e sua família. Chico Rei sabia que ainda havia bastante ouro na mina. O Galanga rinconiano usa a força física e literalmente toma a sua liberdade das mãos de seu algoz. Porém, essas duas figuras estão em uma mesma epopeia afrodiaspórica, que foge dos moldes ocidentais tão acentuados nas narrativas homéricas. Essas narrativas envolvem tensão e emoção, e as cenas não são fixas. Ficção, autoficção, realidade, mito e subjetividades conectam-se através do fio condutor da ancestralidade. Nesse sentido, Denise Carrascosa afirma que

\begin{abstract}
A noção de "afro-diáspora", portanto, na medida de seus deslocamentos e ressignificações politicamente estratégicas, carrega consigo a força, não apenas espacial do deslocamento territorial em forma de iter narrativo (no contraditório entre escravidão-liberdade); mas também movimenta o eixo do tempo em chave mítico-cíclica, que faz girar as noções lineares e causalistas eurocêntricas de passado e presente que construíram "a" história oficial e legível, articulando paradigmas importantes das contraculturas negras da modernidade (CARRASCOSA, 2016, p. 64).
\end{abstract}

Na faixa-título do álbum, o ex-escravizado Galanga comemora a liberdade conquistada, mas sem deixar de olhar para outras dificuldades que continua a enfrentar. Rincón Sapiência tece com bastante cuidado cada linha da música "Galanga Livre". Como a literatura afro-diaspórica "rasura" a linearidade de tempo e espaço estabelecida pela epistemologia ocidental, o personagem rinconiano encontra-se na sociedade contemporânea brasileira canalizando as dores do passado escravocrata e "procurando pela paz em Aruanda”, como a própria letra da música diz.

\footnotetext{
Andar, andar

Minha vida ninguém pode mandar!

Procurando pela paz, Aruanda

Eu não vou bater panela na varanda! ${ }^{13}$ (SAPIÊNCIA, 2017).
} 
Galanga Livre carrega consigo toda força ancestral de Galanga Rei do Congo (Chico Rei): o enfrentamento ao racismo estrutural, presente no segundo país mais negro do mundo; a busca pela recriação/reafricanização do Brasil; a presentifica o rei congolês; dá continuidade à luta dos africanos e afro-brasileiros escravizados no Brasil colônia, e apresenta para qual povo está direcionado o chamado "ódio de classe". O último verso do fragmento apresentado acima evidencia o que estou expondo aqui.

A tensão entre conforto e conflito acompanha Galanga, o fio da ancestralidade e da memória une os dois Galangas a diversas figuras africanas e afro-diaspóricas, como Faraó, ${ }^{14}$ Nefertiti ${ }^{15}$ e Bob Marley. Comungo com Freitas (2016) quando o autor postula que a ancestralidade relaciona-se com outro valor, que é a memória, e esta não diz respeito apenas a um retorno ao passado, mas à possibilidade de reelaboração das experiências vividas a partir do presente - o princípio da ancestralidade vincula o homem a uma rede que o ultrapassa, já que mesmo os mortos ligam-se à sua existência a partir do respeito e do cultivo a essa memória que vai se tecendo em reverência aos mais velhos, símbolos do saber. É possível perceber no próximo fragmento da letra abaixo

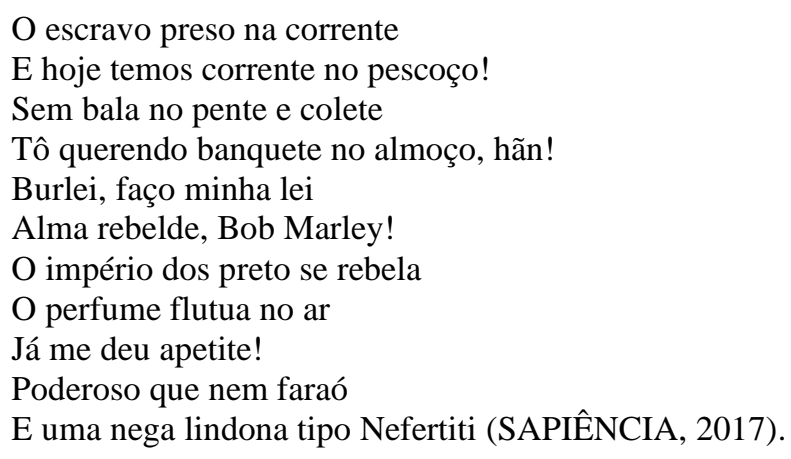

A narrativa de Chico Rei (Galanga), que lutou incansavelmente para alforriar escravizados ex-membros de sua corte e outros, é retomada em Luiz Gama, ${ }^{16}$ José Carlos Limeira, ${ }^{17}$ Abdias Nascimento, ${ }^{18}$ no próprio Rincón Sapiência e em diversos abolicionistas afro-diaspóricos. Diante do exposto, a saga do rei Galanga estende-se à cada geração de afrodescendentes que o incorpora. Para cada Galanga que morre, surge um novo Galanga, um Chico Rei, um "Novo líder". ${ }^{19}$ A literatura afro-diaspórica 
atravessa a tradição e a modernidade, vida e morte, e, por essa razão, os conceitos teóricos ocidentais/eurocentrados não são suficientes para sustentá-la.

O conceito de literatura-terreiro, arquitetado por Henrique Freitas, que, a meu ver, é um grande contributo para os estudos literários afro-diaspóricos e afro-brasileiros, também serve para pensar as narrativas de Chico rei (Galanga rei do Congo) e do Galanga rinconiano.

\begin{abstract}
A literatura-terreiro é aquela que, dentro da cosmogonia africana e/ou afrobrasileira, explora a multimodalidade. Ante os grafocentrismo, logocentrismo e etnocentrismo que orientam a constituição dos saberes tradicionais ocidentais, as experiências ex-cêntricas e descentradas de leitura e escrita na comunidade-terreiro e nas expressões que se orientam por sua lógica desconstroem a perspectiva monológica de produção de sentidos. A apropriação e a geração de significados não ocorrem mais de forma exclusiva por meio do código verbal escrito. Ao contrário, cada vez mais, elas se dão por meio de textos construídos a partir da organização multissemiótica em que a dança, a escrita, a música, as figuras etc. em sua co-ocorrência indissociável (FREITAS, 2016, p. 175).
\end{abstract}

\title{
CONCLUSÃO
}

O que propus neste ensaio foi uma reflexão teórica acerca da literatura afrodiaspórica a partir da narrativa oral do rei Galanga (Chico Rei), reinventada por Rincón Sapiência no álbum Galanga Livre. Assim como o rei do Congo lutava contra a escravidão a que foi submetido, o ideal de liberdade perpassa todo o álbum e ainda insere Rincón Sapiência no panteão dos grandes rappers brasileiros, pela conceitualidade do álbum que ora se apresenta como historiográfico, ora como literário.

Assim, fez-se necessário ativar os referidos operadores teóricos que sustentaram este trabalho, já que são pensadores negros que se debruçam sobre o estudo da música, literatura, sociologia, filosofia, antropologia e etnografia a partir de uma perspectiva africana, afro-diaspórica e/ou afro-brasileira. Essxs autorxs também não dissociam vida e obra, são militantes, membros de organizações e movimentos negros e encaram incansavelmente o racismo estruturante e as práticas epistemicidas que afetam produções negras em todos os campos do saber. Ao fim e ao cabo, Galanga Rei do Congo e Galanga Livre manifestam-se em todas essas plataformas teóricas, e em todxs essxs cientistas afro-diaspóricxs. 
Pela limitação a qual a proposta do ensaio exigiu, não pude tecer uma abordagem teórica mais aprofundada sobre o tema, nem uma análise detalhada das músicas da obra Galanga Livre. Vale ressaltar que o ensaio é uma partícula do trabalho que estou desenvolvendo no curso de Pós-Graduação, em que proponho um estudo comparado entre canções de dois álbuns de rap, o trabalho homônimo do grupo Opanijé, e o próprio Galanga Livre de Rincón. Como ainda não há trabalhos acadêmicos sobre esses autores, eu diria que este funcionou como pioneiro e introdutório.

Sem dúvida, estou diante de um trabalho ainda em processo de gestação e que merece todo o cuidado enquanto ganha forma e corpo, até que venha seu nascimento. Sou grato ao Professor Doutor Henrique Freitas por ter conduzido com maestria o componente curricular para o qual esse trabalho foi designado. Espero que o interesse por esta temática não seja apenas meu, mas de outrxs intelectuais negrxs, ou não. Por enquanto, eu fico por aqui, pois, como dizia o coletivo Obi Ebó, "o tesouro é a estrada, não o destino".

\section{Referências}

BARBOSA, Joaquim Onésimo Ferreira. Narrativas orais: performance e memória. Dissertação (Mestrado em Sociedade e Cultura na Amazônia) — Universidade Federal do Amazonas: Manaus, 2011. Disponível em: https://tede.ufam.edu.br/bitstream/tede/2340/1/Disserta\%C3\%A7\%C3\%A3o\%20\%20Joaquim\%200n\%C3\%A9simo\%20Ferreira\%20Barbosa.pdf. Acesso em: 4 jul. 2019.

CARRASCOSA, Denise. Traduzindo no Atlântico Negro: por uma práxis teóricopolítica de tradução entre literaturas afrodiaspóricas. In: Cadernos de Literatura em Tradução, [S. 1.], n. 16, p. 63-72, 2016. Disponível em: https://www.revistas.usp.br/clt/article/view/115270. Acesso em: 24 jul. 2021.

FREITAS, Henrique. O arco e a Arkhé. Ensaios sobre Literatura e Cultura. Salvador: Ogum's Toques Negros, 2016.

GILROY, Paul. $O$ atlântico negro: Modernidade e dupla consciência. Rio de Janeiro. Editora 34, 2012.

GOUVEIA, Edson Barbosa. Chico Rei: travessia de Rei Galanga a Chico Rei das Gerais. 86 f. Dissertação (Mestrado em Letras) - Centro de Ensino Superior de Juiz de Fora, Juiz de Fora, 2015.

HALL, Stuart. Da diáspora. Identidades e mediações culturais. Organização Liv Sovik; 
Tradução de Adelaine La Guardia Resende et al. Belo Horizonte: Editora UFMG; Brasília: Representação da UNESCO no Brasil, 2003.

HAMPATÉ BÂ, A. “A tradição viva”. In: KI-ZERBO, J. (Ed.). História Geral da África: I - Metodologia e Pré-História da África. 2. ed. Brasília: UNESCO, 2010. p. 167-212.

LAUER, Helen; ANYIDOHO, Kofir (orgs.). O resgate das ciências humanas e das humanidades através de perspectivas Africanas. Brasília: FUNAG, 2016.

MARTINS, Leda Maria. Afrografias da memória. Minas Gerais. MAZA EDIÇÕES,1997.

SANTOS, Amanda Melissa dos. O Grande Anganga Muquixe Chico Rei: a presença do mito negro no Reinado do Alto da Cruz e nas escolas de Ouro Preto/MG. Dissertação (Mestrado) - Universidade Federal de Ouro Preto. Ouro Preto, 2019. Disponível em: https://www.repositorio.ufop.br/bitstream/123456789/11740/1/DISSERTA\%C3\%87\%C 3\%830_GrandeAngangaMuquixe.pdf. Acesso em: 5 jul. 2019.

SAPIÊNCIA, Rincón. Galanga Livre. Álbum completo. Youtube, 2017 Disponível em: https://www.youtube.com/watch?v=7sgsMuqfnWA. Acesso em: 05 jul. 2019.

SILVA, Ricardo Álvares. Herdeiros de Chico Rei: Mito de origem e etnogenese da comunidade quilombola de Pontinha. Disponível em: https://repositorio.ufmg.br/bitstream/1843/BUBD-

ABYHAY/1/herdeiros_de_chico_rei.pdf. Acesso em: 5 jul. 2019.

SOUZA, Ana Lúcia Silva. Letramentos de reexistência. Poesia, grafite, música, dança: hip hop. São Paulo: PARÁBOLA, 2011.

SOUZA, Florentina; LIMA, Maria Nazaré. (Orgs.). Literatura afro-brasileira. Salvador: Centro de Estudos Afro-Orientais; Brasília: Fundação Cultural Palmares, 2006.

RANCIÈRE, Jacques. Capítulo 7. In: - A partilha do sensível. Estética e política. Tradução de Mônica Costa Netto. São Paulo: EXO experimental Org.; Editora 34, 2005.

ZUMTHOR, Paul. Introdução à poesia oral. Tradução de Jerusa Pires, Maria; Lúcia Diniz Pochat, Maria Inês Almeida. São Paulo: HUCITEC,1997.

VASCONCELOS, Agripa. Chico Rei. São Paulo: ITATIAIA,1964. 
${ }^{1}$ A palavra que geralmente é utilizada para definir um artista de rap é rapper ou MC (Mestre de Cerimônia), porém MV Bill aportuguesou o termo, passando a se intitular como rapeiro.

${ }^{2}$ Diferente do produtor musical e do DJ, o beatmaker apenas produz beats (batidas, instrumentais). Alguns realizam também mixagem e masterização, que são processos de acabamento de uma música.

${ }^{3}$ O mesmo que "nome artístico". No movimento Hip Hop, seus membros costumam utilizar os vulgos como autoafirmação político-identitária e caracterização de suas produções artísticas.

${ }^{4}$ Referência ao ativista-político e liderança na causa antirracista, o afro-americano Malcom X.

${ }^{5}$ Música de trabalho (traduzido do inglês).

${ }^{6}$ Extented play (single estendido): compilação de 4 a 6 músicas de trabalho.

${ }^{7}$ Nome que é dado para se referir a cada música de um álbum, EP, mixtape (coletânea) etc.

${ }^{8}$ Manicongo, ou Mwenekongo (língua kicongo), é o nome dado aos governantes do reino do Congo.

${ }^{9}$ Zumbi foi executado em 20 de novembro de 1695. Na mesma data e mês, todo o ano no Brasil, é comemorado o dia da Consciência Negra, em sua memória.

${ }^{10}$ Também chamada de congada, a festa também ocorre em Pernambuco, São Paulo, Rio de Janeiro, Goiás, Espírito Santo, Rio Grande do Sul, Paraná e Pará.

${ }^{11}$ Historiadores, músicos, poetas, responsáveis pela preservação da memória africana e transmissão de conhecimentos a partir da oralidade.

${ }^{12}$ A então princesa Isabel assinou a Lei Áurea em 13 de maio de 1888. Porém, a lei não garantiu nenhuma indenização aos negros escravizados, fazendo com que muitos voltassem à fazenda dos exsenhores de engenho para trabalhar em troca de comida e local para dormir. Após a "abolição", o Brasil iniciara o processo de branqueamento importando mão de obra branca (camponeses europeus) para trabalhar em fazendas e lavouras dos latifundiários.

${ }^{13}$ Referência ao "panelaço", manifestação de grande parte da elite branca brasileira, em oposição ao governo do PT (Partido dos Trabalhadores), e a favor do impeachment da então presidenta Dilma Rousseff. Vários moradores de condomínios de luxo e da classe média batiam panelas de suas janelas e gritavam palavras de ódio ao partido, e aos eleitorxs do mesmo, que são maioria negrxs.

${ }^{14}$ Nome que era dado aos reis do Egito antigo

${ }^{15}$ Rainha da XVIII dinastia do Antigo Egito, esposa do faraó Amenófis IV, conhecido como Aquenáton.

${ }^{16}$ Poeta, rábula, orador, jornalista, escritor brasileiro e o Patrono da Abolição da Escravidão do Brasil. Gama nasceu livre, mas foi vendido como escravizado pelo seu próprio pai. Tornou-se o advogado mais influente na causa abolicionista, tendo libertado mais de 500 cativos. Antes, Luiz Gama havia comprado sua própria liberdade.

${ }^{17}$ Poeta, cronista, contista baiano e militante na causa antirracista. É considerado um dos grandes escritores da literatura negra brasileira. Limeira faleceu em 2016.

${ }^{18}$ Poeta, ator, escritor, dramaturgo, artista plástico, professor universitário, político e ativista dos direitos civis e humanos das populações negras. Abdias foi o primeiro senador negro do Brasil, e um dos principais líderes do Pan-africanismo no país.

${ }^{19}$ Referência a música "Zé do Caroço" da sambista Leci Brandão. 